\title{
Role of Tumour Markers Carbohydrate Antigen 19-9, Carcinoembryonic Antigen, \& Alpha Fetoprotein in Carcinoma Gall Bladder
}

\author{
Saurabh Rai ${ }^{1}$, Chandra Shekhar ${ }^{2}$, Osman Musa ${ }^{3}$, Nisar Ansari ${ }^{4}$, \\ Rahul Agrawal ${ }^{5}$, Rajat Agrawal ${ }^{6}$, Almol Bhore ${ }^{7}$, Shams Alam ${ }^{8}$
}

${ }^{1}$ Department of Surgery, Ram Manohar Lohiya Institute of Medical Sciences, Lucknow, Uttar Pradesh, India. 2, 3, 4, 5, 6, 7, 8 Department of Surgery, Era's Lucknow Medical College, Lucknow, Uttar Pradesh, India.

\section{ABSTRACT}

\section{BACKGROUND}

Gallbladder cancer is recognised as an irreversible malignancy with a high fatality rate. The highest incidence of gall bladder carcinoma is seen in India and Chile, and relatively low level in many Western countries. Gall bladder carcinoma has an extremely poor prognosis, increasing incidence, and diagnosed at an advanced stage despite recent advances in diagnostic modalities. Considering the high rate of mortality attributable mainly to late detection of disease at an advanced stage, early diagnosis remains to be one of the most important determinants of the outcome. This study was conducted to assess the role of tumour markers, namely carbohydrate antigen (CA 19-9), carcinoembryonic antigen (CEA) and alpha fetoprotein (AFP) in the diagnosis of gall bladder carcinoma. We wanted to assess the diagnostic role of tumour markers in carcinoma gall bladder.

\section{METHODS}

Patients with radiologically and histopathologically confirmed diagnosis of carcinoma gall bladder were invited to participate in the study. A thorough history was taken, and relevant examination done as per protocol. All necessary laboratory and radiologic investigations were done according to study design. Assessment of the tumour markers CA19-9, CEA and AFP was done, and values compared with carcinoma gall bladder patients.

\section{RESULTS}

The diagnostic value of tumour markers has been studied in context with histopathological grade as all the cases were histopathologically proven cases of carcinoma gall bladder (Ca GB).

\section{CONCLUSIONS}

The present study showed that CA 19-9 was most effective with regard to its ability to differentiate between different grades of gall bladder carcinoma.

\section{KEY WORDS}

CA 19-9, CEA, AFP, Carcinoma Gallbladder
Corresponding Author: Dr. Chandra Shekhar E Block Rajajipuram, Lucknow - 226017, Uttar Pradesh, India. E-mail:csr13582@gmail.com

DOI: $10.14260 / j e m d s / 2021 / 154$

How to Cite This Article:

Rai S, Shekhar C, Musa O, et al. Role of tumour markers carbohydrate antigen 19 . 9, carcinoembryonic antigen, \& alpha fetoprotein in carcinoma gall bladder. $J$ Evolution Med Dent Sci 2021;10(10):719723, DOI: 10.14260/jemds/2021/154

Submission 28-11-2020,

Peer Review 12-01-2021,

Acceptance 16-01-2021,

Published 08-03-2021.

Copyright (C) 2021 Saurabh Rai et al. This is an open access article distributed under Creative Commons Attribution License [Attribution 4.0 International (CC BY 4.0)] 


\section{BACKGROUND}

Gallbladder cancer is recognised as an irreversible malignancy with high fatality rates. ${ }^{1}$ Interestingly it is infrequent in developed countries but common in some specific geographical regions of developing countries. ${ }^{23,4}$ The highest incidence of gall bladder carcinoma is seen in India and Chile and relatively low level in many Western countries. ${ }^{5}$ Both epidemiology and environmental factors play a critical role in eliciting cancer developing in gallbladder, best exemplified by cholelithiasis and chronic inflammation. ${ }^{6}$

Gall bladder carcinoma has an extremely poor prognosis, increasing incidence, with advance stage at diagnosis, despite the recent advances in diagnostic modalities.7,8 In future the development of potential diagnostic and prognostic markers for the gallbladder disease will yield screening opportunities for those at risk and diagnosed cases of carcinoma gallbladder. ${ }^{6}$ The overall mean survival rate for patients with advanced gallbladder cancer is 6 months, with a 5-year survival rate in $5 \%$ patients. $^{9}$ Early gallbladder cancer (confined to the mucosa), though infrequent, offers the potential for a cure through cholecystectomy. ${ }^{10-12}$ The prognosis and survival rate of gall bladder carcinoma is largely dependent on the stage of disease.

Gall bladder carcinoma is generally diagnosed at later stages. Most of the gall bladder cancer cases have regional disease or distant metastases at presentation. Therefore, the prognosis in gallbladder disease is poor, with 5-year survival rates of $15-20 \%$. Considering the high rate of mortality attributable mainly to late detection of disease at an advanced stage, early diagnosis remains to be one of the most important determinants of the outcome. ${ }^{13,14}$ In the recent years, a number of tumour markers have been identified that help in diagnosis and staging of different types of cancers. ${ }^{15-21}$

Despite promising potential, there are limited studies exploring their diagnostic role in gall bladder carcinoma. Moreover, there are limited studies comparing the diagnostic efficacy of these markers for detection of gall bladder carcinoma or a combined use of these markers to attain a higher accuracy. ${ }^{22-26}$ This study was designed to assess the role of these tumour markers, namely CA 19-9, CEA and AFP in the diagnosis of gall bladder carcinoma. These tumour markers can be assessed using serum as well as tissue specimen and can be measured quantitatively thus, showing potential not only for diagnostic as well as for prognostic purposes.

We wanted to assess the diagnostic role of tumour markers, namely CA 19-9, CEA \& AFP in carcinoma gall bladder.

\section{METHODS}

Analytical cross-sectional study was carried out in the Department of Surgery at Era's Lucknow Medical College (ELMC), Lucknow. Period of study was 18 months from January 1st, 2017 to June 30th, 2018. Patients with histopathologically proven gall bladder carcinoma were included after the diagnosis was made on clinical and radiological basis. Informed consent was taken from all the patients entering in our study. Study was executed after approval by ethical committee in our college.
Patients with clinical, radiological and histopathological confirmed diagnosis of carcinoma gall bladder were included in study. A through history was taken and relevant examination was done as per protocol. All necessary radiologic tests and laboratory investigations were sent according to study design. Assessment of the tumour markers CA19-9, CEA and AFP was done, and values were compared with carcinoma gall bladder patients.

\section{Statistical Analysis}

Analysis of variance (ANOVA) hypothesis test was used for statistical assessment of data. Mean, standard deviation, minimum and maximum of parameters were calculated.

\begin{tabular}{|c|c|c|}
\hline Sl. No. & Tumour Marker & Reference Range \\
\hline 1 & CA 19-9 & $<37 \mathrm{U} / \mathrm{mL}^{27}$ \\
\hline \multirow{3}{*}{2} & \multirow{3}{*}{ CEA } & $<2.5 \mathrm{ng} / \mathrm{mL}$ in non-smokers ${ }^{28}$ \\
\hline & & $<5 \mathrm{ng} / \mathrm{mL}$ in smokers ${ }^{28}$ \\
\hline & & $>100 \mathrm{ng} / \mathrm{mL}$ signifies metastatic cancer ${ }^{29}$ \\
\hline 3 & AFP & $0-15 \mathrm{IU} / \mathrm{mL}^{30}$ \\
\hline \multicolumn{3}{|c|}{ Table 1. Reference Ranges of Tumour Markers } \\
\hline
\end{tabular}

\section{RESULTS}

Age of patients enrolled in the study ranged between 30 and 65 years, mean age of patients enrolled was $47.00 \pm 9.08$ years. Majority of the patients were aged $<=50$ years $(60.0 \%)$. Most common age group was 30 - 40 years $(40.0 \%)$ followed by 51 - 60 years $(36.7 \%)$. Only 1 ( $3.3 \%)$ patient was aged $>60$ years. Majority of the patients enrolled in the study were females (83.3\%), rest $16.7 \%$ patients were males. Complaints were noticed by patients from last 15 days to 1 -year duration. Mean duration of complaints was $7.62 \pm 3.38$ months. Only $10.0 \%$ patients noticed complaints for $<=3$ months. Duration of complaints 4 - 6 months was most common (40.0\%) followed by $10-12$ months (30.0\%). None of the patients enrolled in the study had any family history of gall bladder carcinoma. Only $20.0 \%$ of patients were tobacco chewers, $13.3 \%$ were smokers and $6.7 \%$ were alcohol consumers. Range of serum CA 19 - 9 marker was 2 - 1201 units / $\mathrm{mL}$ while that of CEA was 1.0 - $22.0 \mathrm{ng} / \mathrm{mL}$ and of AFP was 1 - $44 \mathrm{IU} / \mathrm{mL}$, mean values of CA19 - 9, CEA and AFP were $125.85 \pm 221.76$ units / mL, $6.19 \pm 4.81 \mathrm{ng} / \mathrm{mL}$ and $11.27 \pm 10.53 \mathrm{IU} / \mathrm{mL}$ respectively.

\begin{tabular}{|ccccc|}
\hline Parameter & Minimum & Maximum & Mean & SD \\
CA 19-9 $(\mathrm{U} / \mathrm{mL})$ & 2 & 1201 & 125.85 & 221.76 \\
CEA $(\mathrm{ng} / \mathrm{mL})$ & 1.0 & 22.0 & 6.190 & 4.81 \\
AFP $(\mathrm{IU} / \mathrm{mL})$ & 1 & 44 & 11.27 & 10.53 \\
\hline \multicolumn{5}{c}{ Table 2. Serum Biochemical Markers } \\
\hline
\end{tabular}

The smear specimens of patients enrolled in the study were analysed by experienced pathologists where $33.3 \%$ were assessed as grade III, $30.0 \%$ as grade I, $20.0 \%$ as grade II and $16.7 \%$ as grade IV carcinoma.

Out of 30 patients raised CA 19-9 ( $>=37$ units $/ \mathrm{mL}$ ) were observed among $66.7 \%$, raised CEA ( $>=2.5 \mathrm{ng} / \mathrm{mL}$ among non-smokers, > $=5 \mathrm{ng} / \mathrm{mL}$ among smokers) was observed in $70.0 \%$ ) while raised AFP levels were observed among $30.0 \%$ patients only. Positivity rate of AFP (30\%) as compared to CA $19-9(66.7 \%)$ and CEA $(70 \%)(P<0.001)$ was found to be significantly lower. 
CA 19-9 showed a significant increase with increasing histopathological grade i.e., grade IV (429.92 \pm 447.70 units / $\mathrm{mL})$ was maximum while grade I was minimum $(36.76 \pm 32.27$ units / $\mathrm{mL})(\mathrm{P}=0.004)$. CEA level of grade IV (9.16 $\pm 4.49 \mathrm{ng} /$ $\mathrm{mL}$ ) was maximum while that of grade I was minimum (4.24 \pm $3.11 \mathrm{ng} / \mathrm{mL}$ ), though CEA levels also showed an increasing trend with increasing grade, but this association was not significant statistically $(\mathrm{P}=0.309)$. AFP levels of grade I and III were lower as compared to that of grade II and IV but this difference was not significant statistically $(\mathrm{P}=0.143)$

\begin{tabular}{|c|c|c|c|c|c|c|}
\hline $\begin{array}{l}\text { Sl. } \\
\text { No }\end{array}$ & Biomarker & $\begin{array}{l}\text { Grade I } \\
(N=9)\end{array}$ & $\begin{array}{c}\text { Grade } \\
\text { II }(\mathrm{N}=6)\end{array}$ & $\begin{array}{c}\text { Grade } \\
\text { III }(\mathrm{N}=10)\end{array}$ & $\begin{array}{c}\text { Grade } \\
\text { IV }(\mathrm{N}=5)\end{array}$ & $\begin{array}{c}\text { Statistical } \\
\text { Significance } \\
\text { (ANOVA) }\end{array}$ \\
\hline 1. & CA19-9 & $\begin{array}{l}36.76 \pm \\
32.27\end{array}$ & $\begin{array}{l}78.67 \pm \\
28.47\end{array}$ & $82.29 \pm 69.78$ & $\begin{array}{c}429.92 \pm \\
447.70\end{array}$ & $\begin{array}{l}F=5.705 \\
P=0.004\end{array}$ \\
\hline 2. & CEA & $\begin{array}{c}4.24 \pm \\
3.11\end{array}$ & $5.55 \pm 3.85$ & $6.85 \pm 627$ & $9.16 \pm 4.49$ & $\begin{array}{l}F=1.258 \\
P=0.309\end{array}$ \\
\hline 3. & AFP & $\begin{array}{l}6.42 \pm \\
6.96\end{array}$ & $\begin{array}{l}12.69 \pm \\
10.95\end{array}$ & $10.51 \pm 8.22$ & $19.83 \pm 15.99$ & $\begin{array}{l}F=1.973 \\
P=0.143\end{array}$ \\
\hline
\end{tabular}

Out of 30 patients of gall bladder carcinoma, none of the above three markers (CA 19-9, CEA and AFP) were positive for $20.0 \%$ cases, only 1 marker was positive in $23.3 \%$ cases, two markers were positive for $26.7 \%$ cases while all the three markers were positive for $30.0 \%$ patients.

Association between combined positivity rate and histopathological grade was not found to be statistically significant. The diagnostic value of tumour markers has been studied in context with histopathological grade as all the cases were histopathologically proven cases of Ca GB.

\section{DISCUSSION}

Tumour markers, namely AFP, CEA and CA 19-9, have role in detecting gall bladder carcinoma from non-malignant cases. Taking this diagnostic ability of above tumour markers into account their values assessed to analyse the diagnostic capabilities of above tumour markers. For this purpose, a total of 30 clinically or radiologically cases suspected of gall bladder cancer were enrolled in the study. Patients' age was between 30 to 65 yrs. with mean value $47 \pm 9.08$ years. Gall bladder carcinoma is generally shown to be an age-related disease with higher incidence in advanced age. Compared to present study, Kankonkar reported the age range of patients as 38 to 73 years and mean age as $53.45 \pm 11.70$ years. Wang et al. too in their study reported the age range of patients as 48 to 70 years and mean age as $55 \pm 6.4$ years. Mondalet al. too in their study reported the age range of patients as 50 - 70 years. Thus, compared to previous studies, the patients in present study had a relatively younger profile.

The present study had a dominance of females (83.3\%). Although Wang et al. had a higher proportion of females (61.5 $\%$ ) as compared to males (38.5\%) yet the difference between two genders was not as wide as observed in present study. But Mondalet al. in another Indian study, similar to our study had $78.5 \%$ females as compared to only $21.5 \%$ males. The findings in turn suggest that in circumstances like ours, females are at a higher risk of gall bladder carcinoma as compared to males. That was of the view that sex differences showing marked predominance of women over men are more markedly seen in Northern India, Pakistan and in American Indian females.

In present study, duration of complaints ranged from 15 days to 1 year with a mean of $7.62 \pm 3.38$ months. Half the cases had complaints for $<=6$ months. The findings in turn are suggestive of asymptomatic nature of disease which is mainly responsible for its late detection at advanced stages.

The findings of present study were interesting, provided some useful trends regarding the efficacy of different serum tumour markers for assessment gall bladder carcinoma cases. In present study, the usefulness of these markers could be evaluated in terms of sensitivity only. The present study endorsed the high sensitivity of CA19-9 in detection of gall bladder carcinoma as well as its possible usefulness in differentiation of different grades of cancer. Keeping in view the fact that there are a number of other tumour markers too that have shown a better outcome for differentiation among grades of cancer when used in combination.

In present study, mean serum CA 19-9, CEA and AFP levels were $125.85 \pm 221.76$ (range 2 - 120) U / L, $6.19 \pm 4.81 \mathrm{ng} /$ $\mathrm{mL}$ (range $1-22 \mathrm{ng} / \mathrm{mL}$ ) and $11.27 \pm 10.53$ (range 1 - 44) ug / L respectively. In a previous study, compared to present study, Wang et al. in their study reported mean CA 19-9 and CEA levels in gall bladder carcinoma patients as $238.17 \pm$ $346.36 \mathrm{IU} / \mathrm{L}$ and $9.36 \pm 3.58 \mathrm{ng} / \mathrm{mL}$ respectively. Shukla et al. in their study reported mean CA19-9 levels as $211.27 \mathrm{U} /$ $\mathrm{mL}$ in gall bladder cancer cases while $\mathrm{Vij}$ et al. in their study reported mean CEA and AFP levels as $15.1 \mathrm{ng} / \mathrm{mL}$ and 166.5 $\mathrm{ng} / \mathrm{mL}$ respectively in gall bladder cancer cases. An overview of these values in different studies showed a wide variability and no uniformity.

In present study, all the clinically / radiologically suspected cases were histopathologically confirmed as gall bladder carcinoma. With respect to histopathological grade, maximum ( $\mathrm{n}=10 ; 33.3 \%$ ) were identified as grade III followed by grade I $(n=9 ; 30 \%)$, grade II $(n=6 ; 20 \%)$ and grade IV ( $\mathrm{n}=5 ; 16.7 \%)$ respectively. Most of the previous studies evaluating the role of these markers have evaluated their usefulness in context with differentiation of malignant cases from benign cases.

In present study, we chose CA 19-9 > = $37 \mathrm{U} / \mathrm{mL}, \mathrm{CEA}>$ $2.5 \mathrm{ng} / \mathrm{mL}$ in non-smokers and $>=5 \mathrm{ng} / \mathrm{mL}$ in smokers and AFP $>15 \mathrm{IU} / \mathrm{mL}$ as the cut-off. In a previous study, Wen et al. has chosen same cutoff values for CA 19-9 and CEA, however for AFP they chose > $20 \mathrm{IU} / \mathrm{mL}$ as the cut-off. In another study, Loosen et al. chose CA 19-9 cut-off value as > 324.15 IU / mL and CEA > $4.55 \mathrm{ug} / \mathrm{l}$ respectively for prediction of long-term survival of cholangiocarcinoma patients. The selection of cutoff values in different values was dependent on the purpose of the study. In present study, we wanted to evaluate its role in diagnosis of carcinoma gall bladder; however, as all the cases were histopathologically proven cases of gall bladder carcinoma, hence, this role was restricted to evaluation of grade of disease.

At the selected cut-off values, we found $20(66.7 \%)$ cases to be positive for CA 19-9, 21 (70\%) positive for CEA and 9 (30 $\%)$ positive for AFP. Thus, from the point of view of association of their positivity with gall bladder cancer, CA 19-9, CEA and AFP were $66.7 \%, 70 \%$ and $30 \%$ sensitive. With respect to their usefulness in detection of malignancy too, there is no consensus among the researchers. Vij and Baskaran in their 
study denied the significance of both CEA and AFP in differentiation of benign from malignant. They also did not find any association of these two markers with stage of disease or length of survival. However, Wang et al. found values of both CA 19-9 and CEA to be significantly higher in gall bladder carcinoma cases as compared to benign gall bladder disease and healthy controls.

In their study, they reported the sensitivity of CA 19-9 as $71.7 \%$. Natsios et al. too in their study described CA $19-9$ to be $73.3 \%$ accurate in diagnosis of malignancy; however, they did not find serum CEA levels to have a diagnostic value in differentiation of benign and malignant conditions. As such, role of AFP as a discriminant has not been endorsed by most of the workers.

On evaluating the mean serum CA 19-9, CEA and AFP levels among patients with different grades of gall bladder carcinoma, we found a statistically significant association between increasing grade and increasing grade of tumour for CA 19-9, however, failed to derive such an association for CEA and AFP. These findings are in agreement with the observations of Vij and Baskaran who also found CEA and AFP to have a diagnostic value. With respect to CA 19-9, the findings of present study are in agreement with the observations of Shukla et al. who found a significant change in CA 19-9 levels with advancing stage of disease. Kankonkar et al. that assessed all the three markers too found CA 19-9 to be significantly associated with stage of disease but did not find a similar association with CEA and AFP. Among these three markers, the role of CA $19-9$ as a marker for differentiation among different stages of disease has also been endorsed by Wang et al.

\section{CONCLUSIONS}

Association between combined positivity rate and histopathological grade was not found to be statistically significant. The diagnostic value of tumour markers has been studied in the context of histopathological grade as all the cases were histopathologically proven cases of Ca GB. The present study showed that CA 19-9 was most effective with regard to its ability to differentiate between different grades of gall bladder carcinoma.

\section{Limitations}

Limitation of the present study was the absence of any benign case. Owing to this limitation, scope of the present study was limited only to assessment of these tumour markers with regard to grade of the disease. Although, some studies have also evaluated their role in prognosis and prediction of survival, we did not have any follow-up data and hence, we are not in a position to evaluate the same.

Data sharing statement provided by the authors is available with the full text of this article at jemds.com.

Financial or other competing interests: None.

Disclosure forms provided by the authors are available with the ful text of this article at jemds.com.

\section{REFERENCES}

[1] Pesic M, Karanikolic A, Djordjevic N, et al. Clinical characteristics of primary carcinoma of the gall bladder. facta universitatis. Series: Medicine and Biology 2002;9(3):227-30.

[2] Lazcano-Ponce EC, Miquel JF, Munoz N, et al. Epidemiology and molecular pathology of gallbladder cancer. CA Cancer J Clin 2001;51(6):349-64.

[3] Hundal R, Shaffer EA. Gallbladder cancer: epidemiology and outcome. Clin Epidemiol 2014;6:99-109.

[4] Sharma A, Sharma KL, Gupta A, et al. Gallbladder cancer epidemiology, pathogenesis and molecular genetics: recent update. World J Gastroenterol 2017;23(22):397898.

[5] Miura F, Asano T, Araano H, et al. New prognostic factor influencing longterm survival of patients with advanced gallbladder carcinoma. Surgery 2010;148(2):271-7.

[6] Rakic M, Patrlj L, Koplijar M, et al. Gallbladder cancer. Hepatobiliary Surg Nutr 2014;3(5):221-6.

[7] Goldin RD, Roa JC. Gallbladder cancer: a morphological and molecular update. Histopathology 2009;55(2):21829.

[8] Hu ZH, Li ZW, Shen L, et al. Surgical therapy and prognosis of sarcomatoid carcinoma of the gallbladder. Hepatobiliary Pancreat Dis Int 2010;9(2):175-9.

[9] Levy AD, Murakata LA, Rohrmann CA. Gallbladder carcinoma: radiologic-pathologic correlation. Radiographics 2001;21(2):295-314.

[10] Henson DE, Albores-Saavedra J, Corle D. Carcinoma of the gallbladder. Histologic types, stage of disease, grade and survival rates. Cancer 1992;70(6):1493-7.

[11] Wistuba II, Gazdar AF. Gallbladder cancer: lessons from a rare tumour. Nat Rev Cancer 2004;4(9):695-706.

[12] Lai CHE, Lau WY. Gallbladder cancer: a comprehensive review. Surgeon 2008;6(2):101-10.

[13] Pandey M. Risk factors for gallbladder cancer: a reappraisal. Eur J Cancer Prev 2003;12(1):15-24.

[14] Schottenfeld D, Fraumeni JF. Cancer epidemiology and prevention. $3^{\text {rd }}$ edn. Oxford University Press 2006: p. 787800.

[15] Hederstrom E, Forsberg L. Ultrasonography in carcinoma of the gallbladder. Diagnostic difficulties and pitfalls. Acta Radiol 1987;28(6):715-8.

[16] Oikarinen H. Diagnostic imaging of carcinomas of the gallbladder and the bile ducts. Acta Radiol 2006;47(4):345-58.

[17] Canney P, Moore M, Wilkinson P, et al. Ovarian cancer antigen CA125: a prospective clinical assessment of its role as a tumour marker. Br J Cancer 1984;50(6):765-9.

[18] Zhang D, Yu M, Xu T, et al. Predictive value of serum CEA, CA19-9 and CA125 in diagnosis of colorectal liver metastasis in Chinese population. Hepatogastroenterology 2013;60(126):1297-301.

[19] He CZ, Zhang KH, Li Q, et al. Combined use of AFP, CEA, CA125 and CA19-9 improves the sensitivity for the diagnosis of gastric cancer. BMC Gastroenterol 2013;13:87.

[20] Zur B, Holdenrieder S, Walgenbach-Briinagel G, et al. Method comparison for determination of the tumour markers AFP, CEA, PSA and free PSA between immulite 
2000 XPI and dimension vista 1500. Clin Lab 2012;58(12):97-105.

[21] Ghosh M, Sakhuja P, Singh S, et al. P53 and beta-catenin expression in gallbladder tissues and correlation with tumour progression in gallbladder cancer. Saudi J Gastroenterol 2013;19(1):34-9.

[22] Kankonkar SR, Joshi SV, Deshpande RR. Significance of tumour markers in cancer of gall bladder. Open Journal of Oncology 2013;3(1):33-6.

[23] Wang YF, Feng FL, Zhao XH, et al. Combined detection tumour markers for diagnosis and prognosis of gallbladder cancer. World J Gastroenterol 2014;20(14):4085-92.

[24] Wen Z, Si A, Yang J, et al. Elevation of CA19-9 and CEA is associated with a poor prognosis in patients with resectable gallbladder carcinoma. HPB (Oxford) 2017;19(11):951-6.

[25] Loosen SH, Roderburg C, Kauertz KL, et al. CEA but not CA19-9 is an independent prognostic factor in patients undergoing resection of cholangiocarcinoma. Scientific Reports 2017;7:16975.
[26] Ono T, Komatsu M, Hosbino T, et al. Alpha-fetoprotein, carcinoembryonic antigen and carbohydrate antigen 199-producing gallbladder cancer. J Gastroenterol 1996;31(5):742-6.

[27] Jin X, Wu Y. Diagnostic utility of clinical and biochemical parameters in pancreatic head malignancy patients with normal carbohydrate antigen 19-9 levels. Afr Health Sci 2015;15(1):123-30.

[28] Spindler BA, Bergquist JR, Thiels CA, et al. Incorporation of CEA improves risk stratification in stage II colon cancer. J Gastrointest Surg 2017;21(5):770-7.

[29] Lee DS, Kim SJ, Kang JH, et al. Serum carcinoembryonic antigen levels and the risk of whole-body metastatic potential in advanced non-small cell lung cancer. J Cancer 2014;5(8):663-9.

[30] Tangkijvanich P, Anukulkarnkusol N, Suwangool P, et al. Clinical characteristics and prognosis of hepatocellular carcinoma: analysis based on serum alpha-fetoprotein levels. J Clin Gastroenterol 2000;1(4):302-8. 